\title{
ANTIBACTERIAL ACTIVITY OF FLUORIDE COATED HYDROXYAPATITE GRAFT - AN ADDED ADVANTAGE
}

\author{
Vikas Kumar1, Sheela Kumar Gujjari², Madhugiri Prakash Venkatesh'3 , Arnaw Kishore ${ }^{4}$ \\ 1 Postgraduate Student, Department of Periodontics, Jagadguru Sri Shivarathreeswara Dental College and Hospital. \\ ${ }_{2}^{2}$ HOD, Department of Periodontics, Jagadguru Sri Shivarathreeswara Dental College and Hospital. \\ ${ }_{3}^{3}$ Assistant Professor, Department of Pharmaceutics, Jagadguru Sri Shivarathreeswara College of Pharmacy. \\ ${ }_{4}^{4}$ Senior Research Fellow, Department of Microbiology, Jagadguru Sri Shivarathreeswara Medical College and Hospital.
}

\section{ABSTRACT}

\section{BACKGROUND}

As per WHO, a rough estimate $10-15 \%$ of worldwide population suffer from the periodontal disease, which is caused by roughly more than 500 microbes, most of them are commensals. The regenerative treatment for alveolar bones has increased many folds, but still have limitations.

\section{MATERIALS AND METHODS}

Fluoride incorporated Hydroxyapatite has been formulated and antimicrobial property is checked against control strains of $S$. mutans and $S$. orali with double dilution method.

\section{RESULTS}

The Fluoride incorporated Hydroxyapatite has an excellent antibacterial activity and is able to reduce the number of bacterial count, both at pH 5 and pH 7.

\section{CONCLUSION}

Fluoride with bone graft can have added advantage over many alloplast. Its antibacterial property shown in present study can be a building block for further evaluation of its property on periodontal pathogen.

\section{KEYWORDS}

Periodontal infection, Alveolar bone loss, Fluoride incorporated Hydroxyapatite.

HOW TO CITE THIS ARTICLE: Kumar V, Gujjari SK, Venkatesh MP, et al. Antibacterial activity of fluoride coated hydroxyapatite graft - an added advantage. J. Evolution Med. Dent. Sci. 2016;5(72):5232-5235, DOI: 10.14260/jemds/2016/1185

\section{INTRODUCTION}

According to the WHO, periodontal disease is one of the major dental diseases with a prevalence rate of $10-15 \%$ worldwide. ${ }^{1}$ It is an infection that results from an imbalance between periodontopathogenic microorganisms and the local-systemic host defense. ${ }^{2}$ Although more than 500 species have been discovered in oral flora, but only few have been identified as periodontal pathogens. Most of the species are commensals. Recently key stone hypothesis postulated that a pathogenic bacteria, i.e. $\mathrm{P}$ gingivalis alters host mechanism lead to dysbiosis. ${ }^{3}$ Not only these pathogens involves the oral cavity, but systemic conditions also and it has been proven over last two decades by interventional studies with proinflammatory cytokines. ${ }^{4}$

For past twenty years, regenerative treatment options for alveolar bone loss increased the long-term prognosis for those involved teeth. This regenerative approach evolved in multiple directions from bone grafts to membrane to suturing material and technique. Out of all autogenous bone graft is one of the first to be used and still considered gold standard.

Financial or Other, Competing Interest: None.

Submission 30-07-2016, Peer Review 22-08-2016,

Acceptance 29-08-2016, Published 06-09-2016.

Corresponding Author:

Dr. Vikas Kumar

Department of Periodontics,

Jagadguru Sri Shivarathreeswara Dental College and Hospital,

A Constituent College of Jagadguru Sri Shivarathreeswara University,

Bannimantap, Mysuru, Karnataka.

E-mail: vikas.k.kumar@gmail.com

DOI: $10.14260 /$ jemds/2016/1185
But autogenous bone graft has limitations of morbidity or inadequate quantity. Hence, there are numerous synthetic graft developed and being used in Periodontology. Hydroxyapatite is one of them and has been proven to be useful for augmentation procedures in osseous defects. HA is most affordable and biocompatible, because our skeletal structure is made up of hydroxyapatite with traces of other element. It acts as scaffold for bone to form around granules of HA.

Merely debridement of the defect does not remove the pathogen completely, so recently composite graft came into the picture for better and efficient action of the graft material. Using this concept, fluoride can be added to the HA graft as it has been clinically accepted and approved in prevention of dental caries in preventive dentistry for long. Antibacterial action of fluoride is well understood in last 2 decades. Inhibition of glucose transport by downregulating Phosphoenolpyruvate phosphotransferase and $\mathrm{H}^{+}$/ATPase membrane enzymes with decreasing proton motive force is well explained, but still inhibition of enolase enzyme in glucose metabolism by bacteria to form lactic acid is most accepted mechanism of action for fluoride. 5 So, fluoride within bone graft material can serve an important agent to have a check on local pathogen producing acidic environment in surgical bed and promotes better bone regeneration.

Current pilot study is an attempt to formulate fluoride containing HA graft and evaluate its antibacterial property on commensal bacteria. 


\section{MATERIALS AND METHODS}

The present in vitro study was approved by the Institutional Ethical Review Board, JSS Dental College and Hospital, an affiliated institution of the JSS University, Mysore. This study was conducted at Department of Pharmaceutics, JSS College of Pharmacy and Department of Microbiology, JSS Medical College and Hospital, an affiliated institution of the JSS University, Mysore.

\section{Formulation of Fluoride Incorporated Hydroxyapatite}

FA-coated HA graft was formulated according to methodology given by Nordquist WD et $\mathrm{al}^{6}$ at JSS College of Pharmacy, Mysore. Resorbable Hydroxyapatite graft (HA) (300-500 $\mu \mathrm{m})$ was obtained from Eucare Pharmaceuticals (Sybograf). Sodium fluoride salt was obtained for the formulation of fluorapatite-coated HA graft. Procedure for fluoride incorporated Hydroxyapatite graft formulation.

- $4 \%$ sodium fluoride ( $\mathrm{NaF}$ ) solution was prepared.

- Hydroxyapatite graft mixed and reacted for 2 mins.

- The excess fluoride solution was drawn off.

- $\quad$ The FA-coated HA powder washed 3 times with distilled water.

- The powder was then oven dried at $80^{\circ} \mathrm{C}-100^{\circ} \mathrm{C}$.

Gamma sterilisation and packaging was done at Eucare Pharmaceuticals, Chennai.

Confirmation of Fluoride Incorporation in Hydroxyapatite Graft Energy Dispersive X-Ray (EDX)

Analysis with spectroscopy was done for the confirmation of FA-coating on HA graft. Fluoride releasing pattern assessment in normal saline was done at Sri Jayachamarajendra College of Engineering, Mysore in Department of Environmental Sciences; $0.5 \mathrm{~g}$ of Fluorapatite coated Hydroxyapatite bone graft was mixed in distilled water and assessed at 24 and 48 hours with Sension $4 \mathrm{pH} / \mathrm{ISE} / \mathrm{mV}$ laboratory $\mathrm{pH} / \mathrm{ISE} / \mathrm{MV}$ Meter.

\section{Microbiological Analysis}

The microbiological study was carried out in the Department of Microbiology, JSS Medical College and Hospital. Microbial strains S. mutans (ATCC25175) for Tooth associated infection and $S$. oralis (ATCC9811) for tissue associated infection were procured. Standard microbiological procedures were carried to make the double dilution of the Fluorapatite coated Graft solution. The graft was left overnight in $7 \mathrm{pH}$ solution and serial dilution of solution was prepared for the procedure. Cultured microbial strains were incorporated and inoculated for 24 hours. Similar procedure was done at $5 \mathrm{pH}$ also in $1: 1$ dilution. A controlled tube was kept with normal saline in both the procedures.

\section{RESULTS}

\section{Energy Dispersion X-Ray Analysis}

Confirmation of coating of Fluoride in Fluorapatite coated Hydroxyapatite was done using Energy Dispersion X-Ray Spectroscopy and it was observed that distinct fluoride peak was seen at $0.70 \mathrm{KeV}$, which was not found in Hydroxyapatite graft (Fig. 1-4). By weight percentage amount of Fluoride was 0.66 in Fluoride coated HA (0.85 by amount percentage) against nil in Hydroxyapatite.

\section{Fluoride Release Pattern}

The in vitro fluoride releasing pattern in present study was evaluated. The concentration of Fluoride released from Fluorapatite coated Hydroxyapatite prepared bone graft in Distilled Water increased gradually from $1.67 \mathrm{ppm}$ at 24 hours to $2.07 \mathrm{ppm}$ at 48 hours.

\section{Antimicrobial Analysis}

At $\mathrm{pH} 7$, turbidity or growth was seen in $S$. mutans strain at all the dilutions like $1: 1,1: 2,1: 4,1: 8$ including the controls. In case of $S$. oralis the tubes having a dilution of $1: 1,1: 2$ had no turbidity or growth observed while tubes with dilution 1:4 and 1:8 including controls were having turbidity/growth. (The results obtained are as mentioned as in Table 1).

At pH 5 there were no growth or turbidity observed by $S$. mutans or $S$. oralis, while the control tubes were observed having a turbidity at 1:1 dilution. (The results obtained are as mentioned as in Table 2).

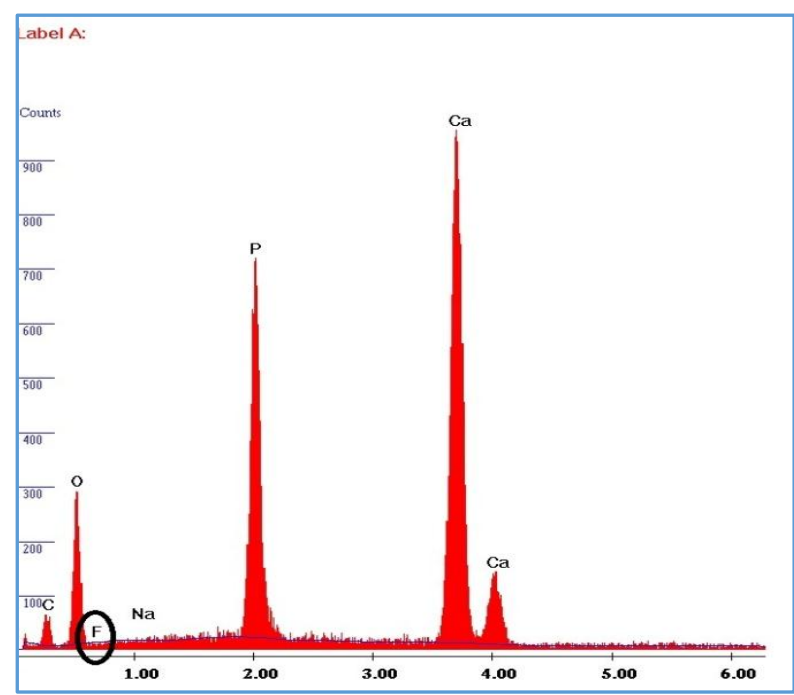

Fig. 1: Energy Dispersion X-Ray Analysis of Hydroxyapatite Crystalline Graft (Without any Fluoride Peak). Energy Dispersion X-Ray Analysis of Fluorapatite Coated Hydroxyapatite Crystalline Graft (With Small Fluoride Peak because of Fluoride

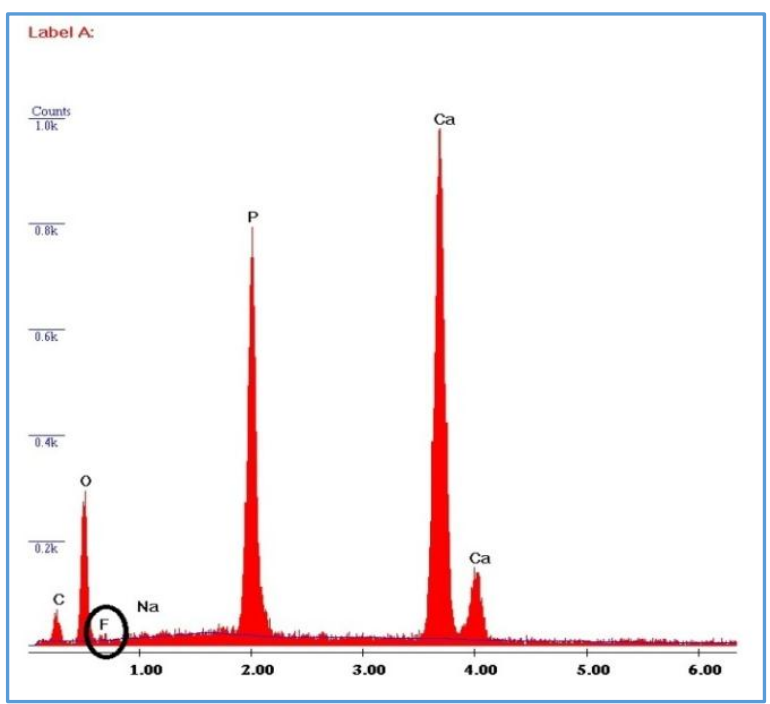

Fig. 2: Energy Dispersion X-Ray Analysis of Fluorapatite Coated Hydroxyapatite Crystalline Graft (With Small Fluoride Peak because of Fluoride Molecular Weight) 


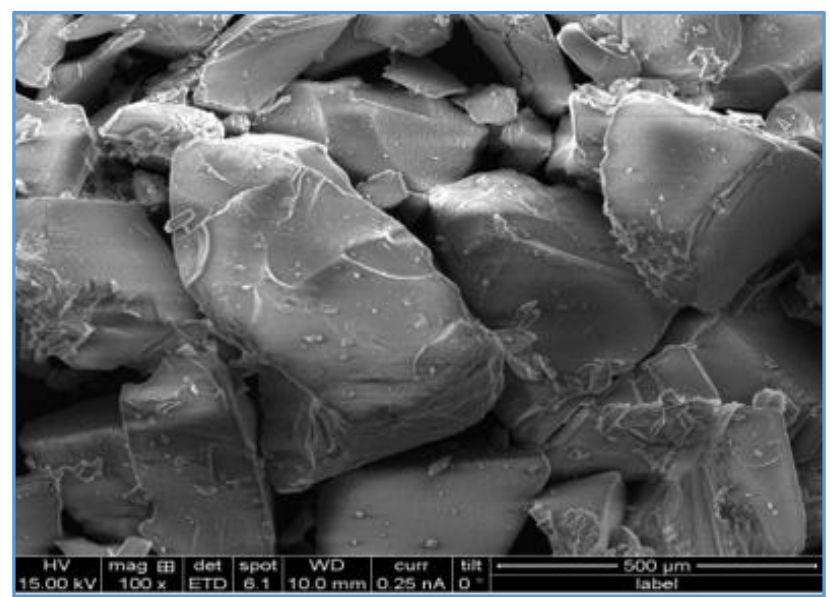

Fig. 3: Surface Spectroscopy of FA Coated HA

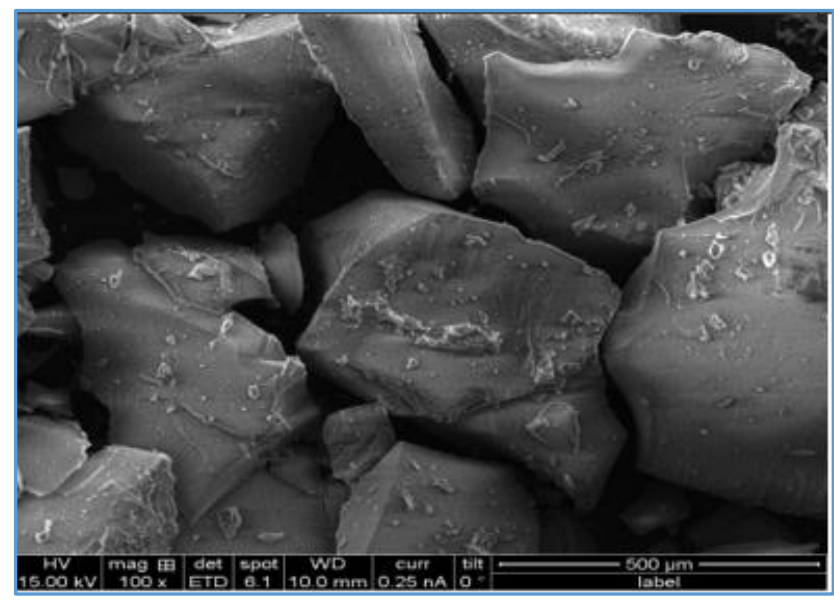

Fig. 4: Surface Spectroscopy of HA

\begin{tabular}{|c|c|c|c|c|c|}
\hline Microorganism & $1: 1$ & $1: 2$ & $1: 4$ & 1:8 & Control \\
\hline S. mutans & Growth present & Growth present & Growth present & Growth present & Growth \\
\hline S. oralis & No growth & No growth & Growth present & Growth present & Growth \\
\hline \multicolumn{7}{|c|}{ Table 1: Results of Dilution at pH 7 } \\
\hline
\end{tabular}

\begin{tabular}{|c|c|c|c|}
\hline & $\mathbf{7} \mathbf{p H}$ & $\mathbf{5} \mathbf{~ p H}$ & Control \\
\hline S. mutans & No Growth & No Growth & Growth present \\
\hline S. oralis & No Growth & No Growth & Growth present \\
\hline \multicolumn{2}{|c|}{ Table 2: Results of Dilution 1:1 at pH 7 and pH 5 } \\
\hline
\end{tabular}

\section{DISCUSSION}

Although, many studies have been done and proved to know the antibacterial activity of fluoride in dentistry and many composite graft being prepared to have antibacterial action of graft material, but no study have been done to author's knowledge that fluoride incorporated graft being tested for its antibacterial activity. The present study attempted to assess the antibacterial activity of fluoride incorporated to HA, which is one of the most commonly used alloplast in the field of Periodontology.

In present study, antimicrobial analysis of fluoride coated HA showed promising results with both the pilot bacterial strain included at different $\mathrm{pH}$. S. oralis a tissue associated with commensal bacteria had higher susceptibility than that of $S$. mutans a tooth associated bacteria at normal $\mathrm{pH}$. But when the $\mathrm{pH}$ decreased to $5, S$. mutans also showed susceptibility towards the fluoride solution. It could be due to diffusion of fluoride into the bacterial cell and down regulation of bacterial enzyme at lower $\mathrm{pH}$ as mentioned by Hamilton et al. ${ }^{5}$ Author in this study postulated that at lower $\mathrm{pH}$, hydrogen fluoride reaction move towards left and will be less in dissociated form. The bound form of hydrogen fluoride will diffuse easily into the cell of bacteria through lipid membrane and again split into proton and fluoride ion under normal or towards basic $\mathrm{pH}$. This will provide more fluoride ion into cell to act on enzymes, which are necessary for survival for bacteria. This is also beneficial in periodontology, because infected root surface will have more of acidic environment in presence of gram negative bacteria due to lactic acid production. This acidic environment not only helps in their own growth, but also provide nexus for other commensals. Fluoride coated graft will not only have check on these bacterial growth in presence of acidic environment.
The results of the present study could not be compared with past studies due to its distinctive approach and design. But HA is being extensively used in periodontal surgery as well as fluoride for its antibacterial property for numerous bacteria. Hydroxyapatite alloplast has been proven to be useful for augmentation procedures in osseous defects in the peri-implantitis lesions and intraosseous periodontal defects. ${ }^{6-8}$ And Fluoride exhibits antibacterial activity against a wide range of putative periodontal pathogens Streptococcus species, Treponema denticola, Lactobacillus, Actinomyces species. ${ }^{9-13}$ A study has been done to determine minimum inhibitory concentration of Fluoride solution for 45 bacterial strains, out of which 22 were oral species and found that some bacterial strains like Actinobacillus actinomycetemcomitans and Capnocytophaga had susceptibility at very low concentration of Fluoride solution. ${ }^{14}$ So, fluoride incorporating in the existing bone graft substitute could be beneficial in restricting bone graft contamination in the infected periodontal site.

An interesting finding has been discovered about Fluoride is that, it not only have antibacterial activity but cell proliferation activity as well. The release pattern of Fluoride from formulated HA graft was little higher (1.67 and 2.07 ppm at 24 and 48 hours respectively) than that of the similar study done in Yokosuka, Japan. But the amount of fluoride released was within the range of its ability to have osteoblastic cell proliferation activity, as it was studied previously. ${ }^{15}$

The antibacterial property and osteoblasts cell proliferative activity of Fluoride can be provided a synergistic effect to HA, which is one of the most commonly used graft material. 


\section{CONCLUSION}

Within the limits of present study, it can be concluded that Fluoride with bone graft can have added advantage over many alloplast. Its antibacterial property shown in present study can be a building block for further evaluation of its property on periodontal pathogen.

\section{REFERENCES}

1. Bali RK, Mathur VB, Talwar PP, et al. National oral health survey and fluoride mapping 2002-2003, India. New Delhi: Dental council of India, 2004.

2. Saini R, Saini S, Saini SR. Periodontitis: a risk for delivery of premature labor and low birth weight infants. J Nat Sci Biol Med 2011;2(1):50-2.

3. Hajishengallis G, Darveau RP, Curtis MA. The keystone pathogen hypothesis. Nat Rev Microbiol 2012;10(10):717-25.

4. Saini R. Dental air force home dental cleaning system: a revolutionary oral hygiene device to prevent systemic diseases caused by periodontal infection. Int J Med Res Health Sci 2013;2(3):431-8.

5. Hamilton IR. Biochemical effect of fluoride on oral bacteria. J Dent Res 1990;69 Spec No:660-7.

6. Nordquist WD, Okudera H, Kitamura Y, et al. Part II: crystalline fluorapatite-coated hydroxyapatite implant material: a dog study with histologic comparison of osteogenesis seen with FA-coated HA grafting material versus HA controls: potential bacteriostatic effect of fluoridated HA. J Oral Implantol 2011;37(1):35-42.

7. Schwarz F, Bieling K, Latz T, et al. Healing of intrabony peri-implantitis defects following application of a nanocrystalline hydroxyapatite (Ostim) or a bovinederived xenograft (Bio-Oss) in combination with a collagen membrane (Bio-Gide). A case series. J Clin Periodontol 2006;33(7):491-9.
8. Moghadam HG, Sandor GK, Holmes HH, et al. Histomorphometric evaluation of bone regeneration using allogeneic and alloplastic bone substitutes. J Oral Maxillofac Surg 2004;62(2):202-13.

9. Kasaj A, Rohrig B, Zafiropoulos GG, et al. Clinical evaluation of nanocrystalline hydroxyapatite paste in the treatment of human periodontal bony defects-a randomized controlled clinical trial: 6-month results. J Periodontol 2008;79(3):394-400.

10. Loesche WJ, Syed SA, Murray RJ, et al. The effect of topical acidulation fluoride on percentage of $S$ mutans and S sanguis in plaque. II. Pooled occlusal and pooled approximal samples. Caries Res 1975;9(2):139-55.

11. Hughes CA, Yotis WW. Effect of fluoride on treponema denticola. Infect Immun 1986;52(3):914-15.

12. Milnes AR, Bowden GH, Hamilton IR. Effect of NaF and $\mathrm{pH}$ on the growth and glycolytic rate of recently isolated strains of oral lactobacillus species. J Dent Res 1985;64(3):401-4.

13. Hamilton IR, Bowden GH. Effect of fluoride on oral microorganisms. In: Ekstrand JO, Fejerskov O, Silverstone LM, eds. Fluoride in dentistry. $1^{\text {st }}$ edn. Copenhagen: Munksgaard 1982:77-103.

14. Mandell RL. Sodium fluoride substitutes of suspected periodontopathic bacteria. J Dent Res 1983;62:706-8.

15. Ohno M, Kimoto K, Toyoda T, et al. Fluoride treated bioresorbable synthetic nonceramic (corrected) hydroxyapatite promotes proliferation \& differentiation of human osteoblastic MG-63 cells. J Oral Implantol 2013;39(2):154-60. 